rate and live birth rates achieved. However, definitive surgical treatment cannot be avoided given the high recurrence rate described in the literature.

\section{IMPLEMENTATION OF THE SENTINEL NODE TECHNIQUE FOR ENDOMETRIAL CANCER IN BELGIUM: A MULTICENTRIC RETROSPECTIVE STUDY FROM 2015 TO 2020}

\begin{abstract}
${ }^{1 ;}{ }^{2} \mathrm{M}$ Luyckx ${ }^{*},{ }^{3} \mathrm{M}$ Fastrez, ${ }^{4} \mathrm{~F}$ Goffin, ${ }^{5} \mathrm{M}$ Jouret, ${ }^{6} \mathrm{Z}$ Al Abkadri, ${ }^{6} \mathrm{~T}$ Willems, ${ }^{7} \mathrm{~F}$ Buxant, ${ }^{8} \mathrm{D}$ Buccella, ${ }^{9} \mathrm{M}$ De Cuypere, ${ }^{9} \mathrm{~A}$ Kakkos, ${ }^{9} \mathrm{~F}$ Kridelka, ${ }^{10} \mathrm{~L}$ Debuyl, ${ }^{10} \mathrm{~B}$ Vandermeersch, ${ }^{11} \mathrm{~K}$ Crener, ${ }^{12} \mathrm{~N}$ Dubois, ${ }^{12} \mathrm{JP}$ Van Gossum, ${ }^{13} \mathrm{~F}$ Grandjean, ${ }^{14} \mathrm{~V}$ Malvaux, ${ }^{14} \mathrm{JC}$ Lousse, 1J Squifflet. 'Cliniques universitaires Saint-Luc (UCLouvain), Gynecology and Andrology, Bruxelles, Belgium; ' ${ }^{2}$ e Duve Institute UCLouvain, TIL's group, Woluwe-Saint-Lambert, Belgium; ${ }^{3}$ Hospital Erasme, gynecology and obstetrics, Bruxelles, Belgium; ${ }^{4} \mathrm{CHR}$ de la Citadelle, gynecology and obstetrics, Liège, Belgium; ${ }^{5}$ Centre Hospitalier de Wallonie picarde (CHwapi), gynecology and obstetric, Tournai, Belgium; ${ }^{6}$ Grand Hôpital De Charleroi - Notre Dame, gynecology and obstetrics, Charleroi, Belgium; ${ }^{7}$ Hôpital Etterbeek-Ixelles/Ziekenhuis Etterbeek-Elsene, gynecology and obstetrics, Ixelles, Belgium; ${ }^{8} \mathrm{CHU}$ Saint-Pierre, gynecology and obstetrics, Bruxelles, Belgium; ${ }^{9}$ Hospital Center Universitaire De Liege, Site N.-D. Des Bruyères, gynecology and obstetrics, Liège, Belgium; ${ }^{10}$ Clinique Sainte-Anne Saint-Rémi, gynecology and obstetrics, Anderlecht, Belgium; ${ }^{11}$ Chu Ambroise Paré, gynecology and obstetrics, Mons, Belgium; ${ }^{12}$ Clinique Saint Jean, gynecology and obstetrics, Bruxelles, Belgium; ${ }^{13}$ Europe Hospitals - St-Michel Site, gynecology and obstetrics, Etterbeek, Belgium; ${ }^{14}$ Saint-Pierre Ottignies Clinic, gynecology and obstetrics, Ottignies-Louvain-la-Neuve, Belgium
\end{abstract}

\subsection{6/ijgc-2021-ESG0.655}

Introduction/Background* Sentinel node is a very powerful tool in endometrial cancer, giving information on nodal status involvement, with low morbidity. Within a few years, it became part of the standard treatment, at least for low and intermediate-risk patients. Its implementation, safety and reliability, and the evolution of the patient have to be monitored to confirm its great added value and its place in the standard of care for endometrial cancer

Methodology We performed a multicenter retrospective review of all endometrial cancer cases in which SN procedures (with/ without pelvic and paraaortic lymphadenectomy) was planned to be performed, from the centers of the gynecological oncology group (ONCO-GF) of the Gynecology and Obstetrics association, french speaking part in Belgium (CR-GOLFB). Academic and non-academic hospitals participate. The study was accepted by the Ethical Committee of the coordinating center of the study (Cliniques Universitaires St Luc) and registered on clinicltrial.gov (NCT02545348).

Result(s)* To date, 233 patients were included in the study but some center have still to send a part of their data. Preliminary data show that $96 \%$ of the surgery we performed by minimally invasive approach. Overall detection rate is $90 \%$ but only $69 \%$ of bilateral detection. Regarding the tracer, the best bilateral detection rate was obtained with Indocyanine green (84\%). With the methylene blue alone, no detection occurs in $22 \%$ of cases. In a preliminary pathological analysis of the sentinel node, $17 \%$ of SN were infiltrated, $8 \%$ with macro metastasis, $2 \%$ of micro metastasis, and $8 \%$ isolated tumor cells (ITC). We did not record any major intraoperative complication, but one late post-operative dead, in a patient with complete pelvic and para-aortic lymphadenectomy with a duodenal breach that leads to late aorticduodenal fistula.

Conclusion* Our preliminary data show a very good detection rate of $96 \%$, even if bilateral detection was only $69 \%$, in a group of patients from academic and non-academic centers. Learning curves and the evolution of the patient must still be evaluated. The complete data will be presented at the congress.

\section{A RANDOMISED PHASE II STUDY OF COMBINATION CHEMOTHERAPY WITH NINTEDANIB/PLACEBO IN ADVANCED/RECURRENT ENDOMETRIAL CANCER. FANDANGO/ENGOT-EN1/FANDANGO}

\begin{abstract}
${ }^{1} \mathrm{M}$ Mirza, ${ }^{2} \mathrm{D}$ Berton, ${ }^{3}$ I Vergote, ${ }^{4} \mathrm{R}$ Depont Christensen, ${ }^{5} \mathrm{~A}$ Floquet, ${ }^{6} \mathrm{~J}$ Maenpaa, ${ }^{7} \mathrm{~B}$ Braicu, ${ }^{8} \mathrm{~S}$ Altintas, ${ }^{9} \mathrm{P}$ Follana, ${ }^{10} \mathrm{~A}$ Ør Knudsen, ${ }^{11} \mathrm{~B}$ Ataseven, ${ }^{12} \mathrm{~F}$ Selle, ${ }^{13} \mathrm{C}$ Lundgren, ${ }^{14} \mathrm{~J}$ Huober, ${ }^{15} \mathrm{M}$ Fabbro, ${ }^{16} \mathrm{H}$ Denys, ${ }^{17} \mathrm{P}$ Heudel, ${ }^{4} \mathrm{M}$ Magnusson, ${ }^{18} \mathrm{~K}$ Lindemann, ${ }^{7} \mathrm{~J}$ Sehouli. ${ }^{1}$ Rigshospitaletd, Denmark; ${ }^{2}$ GINECO: Groupe d'Investigateurs National des Etudes des Cancers Ovariens et du sein and ICO Centre René Gauducheau, Saint-Herblain, France; ${ }^{3} B G O G$ : Belgium and Luxembourg Gynaecological Oncology Group and Universitaire Ziekenhuizen Leuven, , Belgium; ${ }^{4}$ NSGO-CTU; ${ }^{5}$ GINECO: Groupe d'Investigateurs National des Etudes des Cancers Ovariens et du sein and Institut Bergonié, Bordeaux, France; ${ }^{6}$ Tampere University Hospital, Finland; ${ }^{7}$ Charité, Germany; ${ }^{8}$ BGOG: Belgium and Luxembourg Gynaecological Oncology Group and Antwerp University Hospital, Belgium; ${ }^{9}$ GINECO: Groupe d'Investigateurs National des Etudes des Cancers Ovariens et du sein and Centre Antoine Lacassagne Nice, France; ${ }^{10}$ NSGO-CTU: Nordic Society of Gynaecological Oncology - Clinical Trial Unit and University Hospital Odense, Denmark; ${ }^{11}$ NOGGO: Northeast German Society of Gynaecological Oncology and Kliniken Essen Mitte, , Germany; ${ }^{12}$ GINECO: Groupe d'Investigateurs National des Etudes des Cancers Ovariens et du sein and Groupe Hospitalier Diaconesses, Paris, France; ${ }^{13}$ NSGO-CTU: Nordic Society of Gynaecological Oncology - Clinical Trial Unit and Karolinska University Hospital, Stockholm, Sweden; ${ }^{14}$ NOGGO: Northeast German Society of Gynaecological Oncology and University Hospital Ulm, Germany; ${ }^{15}$ GINECO: Groupe d'Investigateurs National des Etudes des Cancers Ovariens et du sein and ICM Val d'Aurelle, Montpellier, France; ${ }^{16} B G O G$ : Belgium and Luxembourg Gynaecological Oncology Group and Gent University Hospital, Belgium; ${ }^{17}$ GINECO: Groupe d'Investigateurs National des Etudes des Cancers Ovariens et du sein and Centre Léon Bérard, Lyon; ${ }^{18}$ Oslo university hospital, Norway
\end{abstract}

\subsection{6/ijgc-2021-ESG0.656}

Introduction/Background* Endometrial cancer (EC) patients (Pts) with advanced and recurrent disease relapse despite treatment with combination chemotherapy and have a short progression-free survival (PFS). Nintedanib $(\mathrm{N})$ is a potent, orally available triple receptor tyrosine kinase inhibitor targeting VEGFR 1-3, PDGFR $\alpha / \beta$, and FGFR 1-3. This study explored the preliminary efficacy of nintedanib in EC.

Methodology The primary objective of this placebo-controlled, randomized study was to evaluate efficacy defined by median PFS of concomitant and maintenance $\mathrm{N}$ against placebo $(\mathrm{P})$ in combination with chemotherapy. Patients with histologically confirmed stage IIIC2 or IVA \& B or relapsed after adjuvant therapy for stage I-III disease; prior surgery; adjuvant chemotherapy; radiation therapy; hormonal therapy in metastatic setting; with measurable/non-measurable disease were permitted. Pts were randomized $1: 1$ to receive $\mathrm{N} 200 \mathrm{mg}$ or $\mathrm{P}$, twice daily days 2-21 during chemotherapy (six cycles of Carboplatin (AUC5) and paclitaxel $(175 \mathrm{mg} / \mathrm{m} 2)$ every 21 days) and continuously in maintenance phase. $\mathrm{N} / \mathrm{P}$ was continued until disease progression, unacceptable toxicity, or withdrawal of consent. Stratification by stage of disease, prior adjuvant chemotherapy and measurable/non-measurable disease. This is an ENGOT Model A study. Clinical trial information: NCT02730416.

Result(s)* 146 of 148 pts were eligible for PFS: 72N/74P; mean age 66yrs; FIGO stage III 18\%, IV 42\%, recurrent 40\%; follow-up 30 mo. $\mathrm{N}$ added to chemotherapy did not improve PFS (119 events) as compared to chemotherapy plus 